Environmental Research Journal 13 (1-4): 21-34, 2019

ISSN: $1994-5396$

(C) Medwell Journals, 2019

\title{
Influence of Population Growth on Socio-Economic Characteristics of Households in South-West Region of Nigeria
}

\author{
Owolabi Babatunde Oluwaseyi \\ Department of Urban and Regional Planning, Federal University of Technology Akure, \\ Ondo State, Nigeria
}

\begin{abstract}
This research focused to access the impact of population growth on the socio-economic status of households in Somolu local government area of Lagos state in South-West region of Nigeria. About 200 respondents were used as the sample size which were obtained using the following processes after paying several research visit to the Somolu local government area in order to gain the first hand information. The survey questionnaires were validated following a pilot test and reliability test. Descriptive statistics provide background information for sample characteristics. Background information includes the profiles of the respondents (gender, role, educational level, sex, household size). Frequency distributions and percentages provided an overview of the collected data. These were displayed in the form of graphs and tables. It was observed that the population of youths within the ages of 25-35 dominates across the four zones. A high proportion of individuals were within the ages of 36-45. This characterizes a population of fertile, actively reproducing individuals. The male population seems to dominate in all the zones, compared to the females. There were a higher proportion of unmarried individuals, among which might also be dating in courtship or living with a significant other without a legal union. There are also a good number of married couples living together in the zones. A high number of participants from Ilaje/Chemist and Bajulaiye had no formal education. More individuals form Fadeyi were educated up to the Tertiary level and the average were distribution was across the primary and secondary levels of education. The highest proportion of the population felt that the increase in population had a negative effect on their health including but not limited to access to healthcare services, access to a clean environment, access to childcare and maternity services. This study attempted to examine the impact of population growth on the socio-economic status of households in Somolu local government area. Findings evidenced a trend of large families with sources of income that is insufficient or not sufficient enough to cater for its members. The households also felt that the effect of increase in population was negative with relation to the health, accommodation, income and livelihood.
\end{abstract}

$\underline{\text { Key words: Influence, population growth, socio-economic characteristics, households, South-West, Nigeria }}$

\section{INTRODUCTION}

Nigeria is the most populous country in Africa and the eighth most populous country in the world with 182 million inhabitants in 2015 . Nigeria accounted for $5 \%$ of births globally but by 2050 it is projected that one in every ten children worldwide will be born in Nigeria, indicating a significant increase in both the absolute number of births and children in Nigeria over the course of the outlook. Despite declining fertility, Nigeria's population is expected to continue to grow to 262 million by 2030 and 398 million by 2050 on current trends.

In 2015, Nigeria was listed as 22nd largest economy in the world however, human development indicators have not kept pace with economic growth. Typical of oil-rich economies, Nigeria exhibits severe economic inequality, poverty and about $62 \%$ of the population lives on $\$ 1.25$ a day or less. Nigeria is ranked 17th of the countries that have the greatest demographic vulnerability in the world. Areas of particularly high stress include political instability, environmental degradation, poverty and hunger. With over 11 million stunted children in 2013, Nigeria ranks second behind India among all countries with the highest number of stunted children.

Though there are many vulnerabilities, population growth can also be an opportunity. One consequence of prolonged population growth coupled with reducing fertility rates is that Nigeria is on the verge of a potential demographic dividend; the economic growth due to the increase in the share of a country's working age population. However, there are a number of underlying vulnerabilities that could transform this opportunity into a risk including persistently low levels of education, sub-optimal employment practices and opportunities and the timing of childbearing. A lack of investment into the human resources of a country in the early stages of 
demographic transition can reinforce a negative feedback loop whereby demographic changes exacerbate underlying vulnerabilities in the economic, social and political dynamics and in turn undermine efforts to reduce the population growth to replacement levels.

The manifestations of poverty cut across nearly all sectors of Nigeria's economy. However, the health impacts of poor living conditions in the country have received the most attention. At least one out of every four children under the age of five in Nigeria was underweight in 2012. In addition, even though Nigeria ranks seventh in population size around the world, more mothers and children die in Nigeria than in any other country, except India. Given Nigeria's rich resource endowment, the level of poverty in the country is concerning. But a large body of literature has emphasized how unlike many other resource-rich nations like Saudi Arabia, Nigeria's rich natural resource endowment has been a curse rather than a blessing to the majority of its populace.

Statement of the research problem: At a population growth rate of $2.8 \%$ per annum between 1952 and 1991 , Nigeria is one of the fastest growing countries in the world. Nigeria is the most populous country in Africa and accounts for one in five of Sub-Saharans people. By 2013, the population forecast for Nigeria is 169.7 million. However, the composition of this population is mainly in the youthful category with $49 \%$ below the age of 21 years and a dependency ratio estimated at $89 \%$. A large proportion of this population favours and is living in the rapidly expanding urban areas, presently estimated at over $45.2 \%$ and will likely hit $55.4 \%$ mark by the year 2015 (Banerjee and Newman, 1991).

Lagos being Nigeria's foremost city is a microseism of the country, it has experienced a rapid and exponential population growth rate in recent decades, coupled with wide spread poverty. Futuristic population projections reveal that due to high fertility trends and massive inflow of people into Lagos on daily basis, the population will continue to grow for many years to come, creating population momentum. Under the given economic conditions of the country, it is exigent to put serious efforts to bring down fertility rate and population growth rate to a lower level from where the econom ic growth can take off for sustained economic development at desired velocity and may be accelerated with the passage of time.

Socioeconomic status of households is an economic and sociological factor. It is the combined total measure of a person's work experience and of an individual or family's economic and social position relative to others. It is based on income, education and occupation. When analyzing a family's social economic status, the household income, earner's education and occupation are examined as well as combined income, versus with an individual when their own attributes are assessed. Rapid population growth in Nigeria is equally associated with unemployment with figures ranging from $17 \%$ per annum for the entire population to $60 \%$ for the youths. This is because job opportunities are fewer than the number seeking for them and stagnating economic performance because a large proportion of available resources is consumed instead of being invested to generate growth (FMH., 1988).

Aim and objectives: The aim of this study is to examine the population growth on the socio-economic status of households in Somolu local government area while the specific objectives are delineated below:

- Access the social-economic characteristics of households in Somolu local government area

- Assess the demographic patterns and fertility trend of households in Somolu local government area

- Investigate the relationship between population growth and economic status of households in Somolu local government area

- Evaluate the residents perception no the impact of these demographic changes on the socio-economic status of their household

\section{Research questions:}

- What is demographic configuration of household members in terms of fertility trends in Somolu?

- What is the nature of the causal relationship between population growth and the social status of households within Somolu?

- What is the nature of the causal relationship between population growth and the economic status of households within Somolu?

- To what extent has the perception of household members changed in Somolu with regards to the prevailing demographic changes?

Significance of study: The study will be of importance to economic planners, policymakers, geographers, economists, students, academicians, professionals as well as government on need to incorporate public planning and policies into the society to broaden the knowledge of individuals on the impact of population growth on the socio economic household status and the country's overall economic status as well.

This study will guide the future researchers on the awareness of the socio economic effects on households status in the study area and other regions. It will also create awareness on the socio economic activities in the study area. Finally, this study will add to the existing literature knowledge on the topic under discuss and create an avenue for future researchers who wish to delve into 
this study to be acquainted of the possible impact of population growth on the socio economic status of households.

\section{Definition of terms:}

Fertility: The total fertility rate in a specific year is defined as the total of children that would be born to each woman if she were to live to the end of her child bearing years and give birth to children in alignment with the prevailing age-specific fertility rates as defined over 5 year intervals. Assuming no net migration and unchanged mortality a total fertility rate of 2.1 children per woman ensures broadly stable population. Together with mortality and migration, fertility is an element of population growth, reflecting both the causes and effect of economic and social developments. The reasons for dramatic decline in birth rates during the past few decades include postponed family formation and child-bearing and a decrease in desired family sizes. This indicator is measured in children per woman.

Doubling time: Doubling time is the amount of time required for a quantity of something to double in either size or value. It is often applied to population growth as the rule of 70 which takes the growth rate over a specific period (as a percent) and divides it into 70 there by giving an approximate doubling time for that population. Thomas Malthus was one of the first to argue that population was likely to grow at an exponential (geometric) rate while food supply would grow at a much slower linear (arithmetic) rate. The primary belief for exponential population growth is that the population will grow much faster as it gets larger, straining society's ability to provide for itself. However, while doubling time can be useful in expressing the potential long-term impacts of population growth, factors such as supplies of various resources, advanced technology or other innovations etc. can have a positive or negative effect on overall population growth and should be taken into account.

Demographic transition: A demographic transition is the term demographers use to describe the movement from high birth rates and high death rates that typically characterize traditional societies to the low birth rates and low death rates that are common in developed, industrialized countries. As a country develops economically the expected transition from a country with high birth and death rates to one with low birth and death rates can be illustrated by the four stages of the demographic transition model.

Stage 1 occurs in a pre-industrial society where death and birth rates are high and relatively in balance, resulting in a slow and steady population growth. In stage 2 , death rates begin to decline with improved food supplies and sanitation which results in a decrease in disease and an overall increase in life span. Stage 3 sees a decline in birth rates due to a reduction in subsistence agriculture an increase in women's education and access to contraception and other social factors. This is also the stage where population growth begins to level off. Stage four shows stabilization in population growth with both low birth and death rates. However, as the population ages, total population can decline (negative growth) as there are less births than deaths.

Population pyramids: Population pyramids are back-to-back graphs normally forming the shape of a pyramid that show the distribution of a population by age and sex. Males typically form the left side graph while females form the right side. Age is represented in 5-year groupings along the $\mathrm{Y}$-axis with population along the $\mathrm{X}$-axis. A pyramid with a wide base that gradually narrows illustrates a rapid population growth with high birth and death rates and an increasing proportion of children, typical of most developing countries. An aging population is one with low birth and death rates have a smaller pyramid base and a bulging middle that slowly moves upward over time. Population pyramids can be useful in identifying changes in population over time, including trends in birth and death rates or other cohort-or sex-specific trends that may necessitate additional government planning.

Study area: Lagos area is located in South-Western part of Nigeria within approximately between latitudes $6^{\circ} 22^{\prime} \mathrm{N}-6^{\circ} 52^{\prime} \mathrm{N}$ and longitudes $2^{\circ} 42^{\prime} \mathrm{E}-3^{\circ} 42^{\prime} \mathrm{E}$ (see Fig. 1). The state in which the city is located is flanked in the North and East by Ogun state in the West by the republic of Benin and in the South by the Atlantic Ocean/Gulf of Guinea. The total landmass of the state is approximately $3.345 \mathrm{~km}^{2}$ which represents almost $0.4 \%$ of the total land area of Nigeria. Physically it is the smallest though most populated state in the country with an estimated population of roughly 10 million inhabitants i.e., approximately $10 \%$ of the total population of Nigeria, Africa's most populous country.

Somolu is a residential suburb in Lagos state; Somolu local government is part of the twenty local government areas in Lagos state, Nigeria and falls on a coordinate of $6^{\circ} 32^{\prime} 27^{\prime \prime}$ North, 3 22'14" East (Fig. 2). Somolu is bounded by Lagos Mainland local government areas to the South-West. The Lagos lagoon to the South-East, Kosefe local government areas to the North East and Mushin to the North West. Somolu is a wetland area, located in South Westland of coast land of Nigeria. The dominant vegetation of the state consists of freshwater and mangrove. The national population commission census of 2006 final report estimated the populations of Somolu with inhabitants of 403,569. 
Environ. Res. J., 13 (1-4): 21-34, 2019

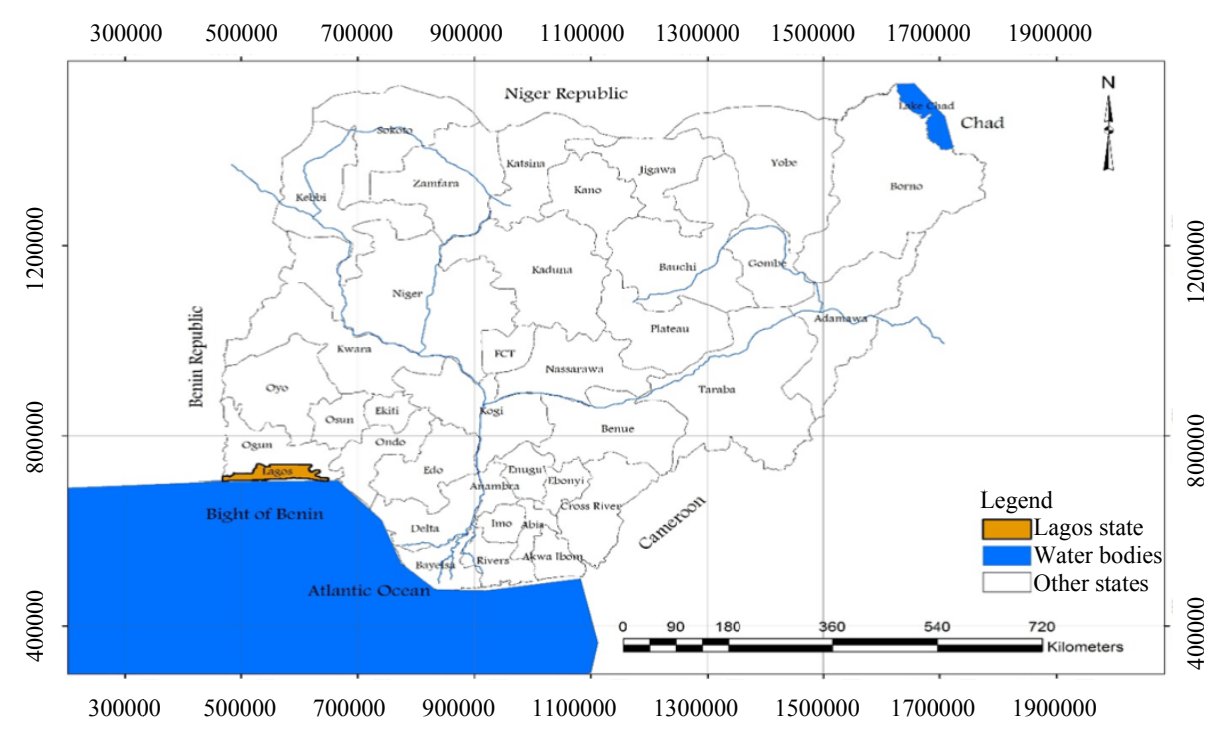

Fig. 1: Lagos state within the national setting; Lagos state Ministry of Physical Planning and Urban Development (2018)

Somolu is the elite printing hub in Nigeria. A settlement includes Fadeyi, Bariga, Ilaje, Somolu and Bajulaiye.

The climate of Somolu local government is a Tropical Savannah Climate (Kop pen Climate Classification AW) that is similar to that of the other part of South Western Nigeria. There are 2 rainy seasons with the heaviest rains falling from April-July and a weaker rainy season in October and November. There is a brief relatively dry spell in August and September and a longer dry season from December-March. Mostly rainfall between May and July averages over $400 \mathrm{~mm}$ (15.7in) while in August and September it is down to $200 \mathrm{~mm}$ (7.9in) and is accompanied by Harmattan winds from the Sahara deserts which between December and February can be quite strong.

\section{Conceptual framework and literature review: Literature review:}

Demographic pattern and fertility trend: Published studies have offered several hypothesis and explanations for the persistence of high fertility levels in developing countries. The factors identified include the loss of focus on family planning programs in the development agenda of these countries following new health challenges such as HIV/AIDS. The impact of HIV/AIDS epidemic on infant and child mortality changes in proximate determinants to fertility, changing attitudes towards family size preferences and family planning (Bongaarts, 1978) and changes in levels of contraceptive use and socio-economic development as reflected in changes in women's education, infant and child mortality and real per capita economic growth (Bongaarts, 1978). In Kenya, West off and Cross illustrated differentials in fertility outcomes by showing that the trajectory of fertility varies between subgroups with certain socio-economic characteristics. Ezeh et al. confirmed these differentials for four countries in Eastern Africa.

A previous analysis in Nigeria (Reed and Mberu, forthcoming) suggested similar differentials with variations in fertility outcomes identified across geopolitical zones, education, household wealth and place of residence. The North East (TFR 6.3) and North West (TFR 6.7) geopolitical zones of Nigeria (predominantly Muslim and populated by Hausa, Fulani and Kanuri ethnic groups) have pre-transition TFRs. The TFR rates for these two zones increased between 2003 and 2008 and decreased marginally in 2013. All of the geopolitical zones in the southern part of Nigeria (predominantly Christian and populated by Yoruba, Igbo and other ethnic groups) experienced "stalled fertility declines" between 2003 and 2008 and again between 2008 and 2013. The Southern zones have current TFRs ranging between a low of 4.3 (South South) and a high of 4.7 (South East) which is over two children per woman lower than the TFR of the two core Northern zones. Since, 2003, the North central zone has had a TFR that is lower than that of the other Northern zones but which is still on average, one child higher per woman than the TFR of the Southern zones in 2003, 2008 and 2013.

Quantitative and qualitative studies have identified ethnicity and religion as significant determinants of reproductive behavior and fertility outcomes, particularly in some parts of Northern Nigeria. A recent qualitative study (2007-2008) implemented in the states of Kano and Jigawa found that fertility is a key socio-political, cultural and economic resource in the region. The same study 
identified several factors that contribute to the continued high fertility levels there such as the Koranic inheritance doctrine (which engenders childbearing competition among co-wives in mostly polygynous households) and the depiction of contraceptives as against Islamic doctrine and injurious to women's health in dominant local religious and cultural discourses.

A part from perspectives anchored in religion, other explanations of drivers of fertility in Northern Nigeria include the young age at which most women continue to marry, polygyny and divorce, confusion regarding expectations surrounding spousal communication on fertility and reproduction the marked high status attached to having large families the persistent unavailability of contraceptives and trustworthy family planning providers (especially in rural and semi-rural areas) and the general lack of adequate and comprehensive information on contraceptives in the region. Despite widespread pro-natalist beliefs and opinions, it is important to note the existence in Northern Nigeria of a contrary perspective that supports fertility regulation. This perspective holds that because Islam recognizes the centrality of the family to social life, matching family size with economic resources is a key to rearing children who will not bring disrepute to the Islamic religion.

Despite a fair amount of existing research about fertility in the region, the quantitative ranking of predictors and determinants of fertility and their relative importance in predicting fertility outcomes has yet to be determined. As the country looks forward to a possible demographic dividend it is important that these factors be highlighted, understood and targeted with policy and program interventions in order to better understand the country's national and sub-national population and development trajectory.

Relationship between population growth and economic development: Onwuka evaluated the impact of growing population on economic growth in Nigeria between 1980 and 2003 using OLS regression model. The study relied on annual time series data for its analysis, among the variables of interest incorporated in the model are GDP growth rate, population, growth rate of population, lagged per capita output, oil production, agricultural output among others. The empirical result showed that negative relationship existed between the core variables (i.e., population growth and economic growth) during the period considered.

However, Adewole undertook a research to unravel the highly contentious relationship between the effects of population on economic growth in Nigeria using an annual time series data covering the period of 1981-2007. The researcher chose OLS regression method for analysis, variables included in the model are Real Gross Domestic Product (RGDP), population and Per Capita Income
(PCI). The researcher found among other things that a strong positive relationship existed between population and economic growth (measured as both RGDP and PCI) during the period considered.

Oramah studied the effects of population growth on Nigeria economy using a double time growth analysis. The researcher highlighted the need for population control in Nigeria by explaining the potential danger that can ensue from disregarding trend at which population is growing worldwide. The researcher focussed more on the impact of population growth on non-renewable resource consumption and depletion, land degradation and waste disposal, weather modification, rapid urbanisation and even desertification. Among the factors identified as influencing population size in Nigeria are religion, education, male-child preference, old-age social security, high infant mortality etc.

Nwosu et al. in an empirical research studied the relationship between population growth and economic growth in Nigeria between 1960 and 2008 using annual time series data. OLS techniques were combined with granger causality test for the study. The core variables included in the model were GDP and population growth. The researchers found among other things that population growth has a significant impact on economic growth during the period under-studied; the researchers also established that a sustainable long-run relationship between economic growth and population growth.

Kothare (2006) embarked on a research with a view to establishing the relationship between population growth and economic growth in India. The study covered all provinces in India and covered a period of 1988-1998. The researcher employed the combination of descriptive and analytical statistical tools on the data obtained on variables of interest from India. The empirical result of the study revealed that population growth has significantly and positively impacted economic growth during the period considered. The researcher concluded by showing that the result is valid for both short-run and long-run situation.

Ruel (2003) empirically measure the economic association between population growth and economic growth in Africa using Johansen and Granger-causality techniques. The study is based on annual time series data collected on the variables of concern from the two selected countries (Nigeria and Coted'ivoire). The estimation results showed that the variables are co-integrated that is long-run relationship existed between the variables in Nigeria but not in Coted'Ivoire. The results further revealed a negative long-run causal relationship between the two variables of concern in Nigeria (i.e., population growth negatively affects economic growth) in the long-run. In Coted'Ivoire, the results showed that population growth causes economic growth only in the short-run. 
Dao (2012) examined the relationship between population and economic growth in Africa using data that covered selected forty-five African economies. The researcher employed the used of panel data regression analysis for the study, among the variables listed in the model include fertility rate, per capita GDP growth, trade openness, dependency ratio (old and young) among others. The researcher deduced from the findings that the relationship between population growth and per capita GDP growth is linear and negative. The findings further revealed that fertility rates have a negative impact on economic growth and also that old dependency ratio positively affects per capita GDP growth.

Population growth and social status: Measuring household welfare: due to its clearer policy implications and the complexity involved in other conceptualizations of household welfare, income is the most preferred measure of living standard (Montgomery et al., 2000). But the variability in sources of income, its seasonal nature in agrarian societies and the paucity of income data resulting from difficulty involved in collecting accurate information about earnings, make income a less preferred measure in resource-poor countries like Nigeria (Bane and Ellwood, 1986; Sahn and Stifel, 2003). Income-poverty also provides weak assessment of the causes of poverty there by making interventions less feasible (Carter and May, 1999). There is therefore, growing demands for alternative measures of household welfare and poverty in the poor countries like Nigeria (Falkingham and Namazie, 2002; Sahn and Stifel, 2003).

Economists have widely employed consumption expenditure, a money-metric alternative measurement of standard of living in many developing countries (Falkingham and Namazie, 2002; Sahn and Stifel, 2003). Adjusting consumption expenditure for variations in household sizes produces household per capita expenditure on consumption which is a more preferred measure of household welfare than consumption expenditure (Montgomery et al., 2000; Ravallion and Chen, 1997).

However, collection of consumption expenditure data is plagued with reliability issues and the data gathering is cumber some. More so the widely available Demographic and Health Survey (DHS) and other social survey data from many Sub-Saharan African countries, lack information on consumption and expenditure (Mckenzie, 2005). Thus, researchers have adopted alternative measures of socioeconomic well being in the region, notably the wealth or asset index. Asset index and consumption expenditure are both imperfect proxies for household welfare and so they some what differ in their rankings of households and in their estimates of household poverty (Sahn and Stifel, 2003). Both the wealth index and consumption expenditure measure long-term socioeconomic status of households but information about household assets is easier to collect, more cost-efficient and produces more reliable data (Bollen et al., 2002).

The asset index method provides a relative assessment of living conditions which involves ranking households (e.g. in quintiles) based on their ownership of an array of assets. Asset poverty or the wealth index has been widely used in the study of HIV prevalence, gender issues, fertility, child mortality, contraceptive use women's reproductive health and so on (Caroline et al., Falkingham and Namazie, 2002).

The adoption of the asset-based measure is premised on the idea that a goal of most poverty alleviation programs is to increase ability of individuals and households to acquire income generating assets (Sahn and Stifel, 2003). Yet, assets are not only discrete in nature but they are also durable. This means that asset index provides an ambiguous long term household economic status that is less responsive to short-term economic shocks (Falkingham and Namazie, 2002). In times of economic difficulty, individuals may prefer to lessen their food and other household expenditure while preserving their household assets. At the same time, changes in assets may not necessarily mean changes in household welfare (Falkingham and Namazie, 2002). Wealth index is therefore, limited in monitoring people's experiences of poverty over time.

Unlike per capita consumption expenditure that adjusts for variability in price (but often due to problems involved in valuing assets), researchers usually assume comparable prices and/or values of assets across space (Bollen et al., 2002). Many studies also fail to adjust for variations in household sizes and compositions when constructing the wealth index. Therefore, relatively large and poor households may be ranked high on the wealth quintiles when they report more assets, simply due to their sizes.

More so asset index is derived from aggregate country-level data that raises the issue of validity of the measurement, particularly in the rural areas (Falkingham and Namazie, 2002). Asset measures sometimes reflect mere geographic proximity to public infrastructure (Falkingham and Namazie, 2002) and many assets used to estimate asset poverty such as electricity, pipe borne water, flush toilets and cement floor are more urban than rural in nature (Filmer and Pritchett, 2001). It is therefore not surprising that assets predict poverty better in rural areas than in the urban centers (Baulch, 1996). Previous studies have also reported cross-country, regional and state variations in the relative importance of assets (Filmer and Pritchett, 2001). Whereas household goods like television, radio and fridge better distinguish wealth classes in Jamaica, access to pipe-borne water assesses wealth better in Madagascar (Sahn and Stifel, 
2003). The choice of asset indicators is limited to those available in surveys, particularly the Demographic and Health Survey (DHS) (Falkingham and Namazie, 2002). The DHS not only has limited number of durable goods with no information about their quantity or quality but it also fails to include many assets commonly owned by the poor and rural dwellers (Brooks-Gunn et al., 1993). This may be because the assets in DHS were not originally intended to measure household socioeconomic status (Falkingham and Namazie, 2002). Although, the world bank developed a measure of relative economic status based on housing characteristics, durable consumer goods, water and sanitary facilities, among other amenities.

Different studies construct wealth indices using different sets of wealth indicators despite variations in household ranking based on the choice of assets (Brooks-Gunn et al., 1993; Montgomery et al., 2000) and how the scale is constructed. Moreover, the wealth index is constructed from several variables, many of which may confound the associations between sociodemographic characteristics and health outcomes (Montgomery et al., 2000). The components of the wealth index affect and are affected by different socioeconomic and health factors (Brooks-Gunn et al., 1993).

There is therefore, no theoretical underpinning as to what specific aspect (s) of household socioeconomic status the wealth index assesses (Filmer and Pritchett, 2001). In fact, the asset index is not based on actual experiences of poverty. Rather, it assumes close relation between material possessions and other aspects of wellbeing. However, socioeconomic wellbeing is multidimensional (Falkingham and Namazie, 2002) and highly complex. It requires approaches beyond material consumption or resources (Falkingham and Namazie, 2002).

The relative strength of each dimension of household welfare and the interactions of the different measures of socioeconomic status are important to intervention programs and policies. Food and water are two basic needs for survival, inadequacy of which suggests extreme or hardcore poverty (Filmer et al., 2000). Questions about food security and water access are relatively simple to ask and food insufficiency has been found to be a powerful correlate of money-metric poverty (Falkingham and Namazia, 2002; Mckenzie, 2005).

Household livelihoods based on food and water access: a society is food insecure when some or all of its people, at some point in time do not have access (physical, social and economic) to sufficient, safe and nutritious food that they need or that they prefer to have in order to lead active and healthy lives (Zimmerman and Carter, 2003). Food insecurity at the household level involves unreliable and or insufficient quality and quantity of nutritionally adequate food. The theoretical understanding of the problem of food insecurity has evolved over time from simply a failure of agricultural production to "a failure of livelihoods to guarantee access to sufficient food at the household level". But except in rare instances of sudden surge in food prices or problems with food supply, household food insecurity is highly invisible to the public gaze; it is a problem often relegated to the household level (Maxwell et al., 2008). Nevertheless, household food security, being an aspect of poverty is associated with maternal and child wellbeing, human capital development, contraceptive use risky sexual behavior, risks of contracting STIs including HIV, suicidality, chronic diseases, among other outcomes (Zimmerman and Carter, 2003). Globally, simulation studies show that as many as five million to 170 million additional people are at risk of hunger by 2080 .

Sub-Saharan Africa has the highest incidence and depth of poverty and remains the only region of the world being threatened by widespread persistent food insecurity and famine. It replaced East Asia as the region with the highest incidence of extreme poverty in the world between 1981 and 2001. The high fertility countries in the region are particularly prone to the problem of food insufficiency because rapid population growth is closely related to the problem of household livelihood, it elevates levels of food demands, increases competition for land and water resources as well as poses environmental challenges. Unsurprisingly, over $40 \%$ of the residents of the most populous country in Sub-Saharan Africa-Nigeria-are food insecure (Amaza et al., 2006). Some estimates are larger than 60\% (Agani et al., 2006; Babatunde et al., 2007).

Although, problems with household livelihoods are more pronounced in the developing world there are limited studies of household welfare, based on food access in resource-poor settings (Grootaert and Kanbur, 1995). Also, due to the reciprocal relationship between HIV/AIDS and food insecurity (Oluyole et al., 2009), the existing analyses of food insufficiency in developing countries have been predominantly conducted in relation to HIV/AIDS. However in South Africa and perhaps elsewhere, HIV, unlike other diseases is more prevalent in the wealthier segment of the population. In Nigeria, the few studies of food insecurity are based on limited geographic coverage-mostly one city. Oyefara studied food insecurity among the female commercial sex workers in Lagos metropolis; Amaza et al. (2006) examined food insecurity in Borno state; titus and in urban part of Lagos.

Food poverty and water access measures are less susceptible to many of the issues arising from studies of household socioeconomic status using other measures, especially, validity and reliability issues, problems with under reporting and difficulty deriving monetary or use values of consumption. Like consumption and 
expenditure measures, food poverty estimates are derived from retrospective recollection of food consumption in the past 7 days. However, unlike consumption expenditure, eating patterns are less sporadic and experiences of hunger should loom longer in people's minds, especially in households that are affected over a relatively long period of time. Food insufficiency and limited water access are also limitless by space and time. Whereas previous studies have mostly lumped water access with other components of the index of living standards (Montgomery et al., 2000), access to water is particularly advantageous over money-metric measures of poverty because it captures an aspect of poverty that cannot be easily monetized in surveys.

National population policy: On February 4, 1988, the federal government of Nigeria approved the National Policy on Population for development in response to the pattern of population growth rate and its adverse effects on national development. Emerging issues such as HIV/AIDS, poverty and gender inequality gained wider recognition. This necessitated a review of the 1988 National Population Policy, giving way to the national policy on population for sustainable development which was signed in January, 2004 by Chief Olusegun Obasanjo then president and commander-in chief of the armed forces of the Federal Republic of Nigeria.

The policy recognizes that population factors, social and economic development and environmental issues are irrevocably interrelated and are therefore, critical to the achievement of sustainable development in Nigeria. The overall goal of the national policy on population for sustainable development is to improve the quality of life and standard of living of the Nigerian population. This is to be achieved through the attainment of a number of specific goals that include:

- Achievement of sustainable economic growth, protection and preservation of the environment, poverty eradication and provision of quality social services

- Achievement of a balance among the rate of population growth, available resources and the social and economic development of the country

- Progress toward a complete demographic transition to a reasonable growth in birth rates and a low death rate

- Improvement in the reproductive health of all Nigerians at every stage of the life circle

- Acceleration of a strong and immediate response to the HIV/AIDS pandem ic and other related infectious diseases

- Progress in achieving balance and integrated urban and rural development
The national policy on population for sustainable development operates on the principle that achieving a higher quality of life for people today should not jeopardize the ability of future generations to meet their own needs. To guide policy, programme planning and implementation the following targets were set:

- Reduce the national population growth rate to $2 \%$ or lower by 2015

- Reduce the total fertility rate by at least 0.6 children every 5 years by encouraging child spacing through the use of family planning

- Increase the contraceptive prevalence rate for modern methods by at least two percentage

- points per year through the use of family planning

- Reduce the infant mortality rate to $35 / 1,000$ live births by 2015

- Reduce the child mortality rate to $45 / 1,000$ live births by 2010

- Reduce the maternal mortality ratio to $125 / 100,000$ live births by 2010 and to 75 by 2015

- Achieve sustainable universal basic education as soon as possible before 2015

- Eliminate the gap between males and females in school enrolment at all levels and in vocational and technical education by 2015

- Eliminate illiteracy by 2020

- Achieve at least a $25 \%$ reduction in HIV/AIDS adult prevalence every 5 years

\section{Conceptual framework}

The malthusian theory: Thomas Robert Malthius argued that population multiplies geometrically and resources arithmetically; therefore whenever the food supply increases, population will rapidly grow to eliminate the abundance. The rapid increase in the global population of the past century exemplifies Malthus's predicted population patterns; it also appears to describe sociodemographic dynamics of complex pre-industrial societies. This theory is applicable when studying the Nigerian population, considering the gross disparity in agricultural resources and the demand for them.

The demographic transition theory: Warren Thompson postulated that there is a transition from high birth and death rates to lower birth and death rates as a country or region develops from a pre-industrial to an industrialized economy system. The transition involves 4 stages.

Pre-industrial society; death rates and birth rates are high and roughly in balance. Population growth is typically very slow in this stage because society is constrained by the available food supply. Developing country; the death rates drop quickly due to improvements in food supply and sanitation which increases life expectations and reduce diseases. 
Birth rates fall due to various fertility factors such as access to contraception, increase in wages, urbanization a reduction in the status and education of women a reduction in the value of children's work an increase in parental investment in the education of children and other social changes.

Birth rates and death rates are both low. As the large group born during stage two ages, it creates an economic burden on the shrinking working population.

Nigeria, the most populous country in the African continent can be said to display a "Stage two demographic transition-like trend". The negative effects might be evident in the utilization of resources and ultimately overall development.

Leibenstein critical minimum theory: According to Prof., Harvey Leibenstein the overpopulated and underdeveloped countries are characterized by the vicious circle of poverty. They have low per capital income his "Theory of critical minimum effort" is an attempt to provide a solution to this economic problem. According to him critical minimum effort is necessary to achieve a steady economic growth raising per capita income. The main idea of the theory is that economic growth in the underdeveloped and overpopulation countries is not possible unless a certain minimum level of investment is injected into the system as a consolidated dose that pulls the system out of doldrums.

Leibenstein's theory recognizes population growth as a function of per capita income. It is related to the various stages of economic development. At the subsistence equilibrium level of income, fertility and mortality rates are the maximum consistent with the survival rate of population. Now if the per capita income is raised above the subsistence equilibrium position the mortality rate falls without any drop in the fertility. The result is an increase in the growth rate of population. Thus an increase in the per capita income tends to raise the growth rate of population. It is only up to a point. Beyond that the increase in the per capita income lowers the fertility rate and as development gains momentum, the rate of population growth declines. The Leibenstein argued that with the increase in per capita income, the desire to have more children declines. Specialization leads to increasing income levels and the consequent-social and economic mobility make it a difficult and costly affair to support a large family.

Hence, growth rate of population becomes constant and then starts declining gradually as the economy gradually advances towards the path of sustained development. According to Leibenstein, a biologically maximum growth rate may be about 3 or $4 \%$. Leibenstein, thus suggests to make sufficiently the necessary critical minimum effort, so as the control such a very high population growth. The theory is applicable when trying to study the country's population growth rate using per capita income.

\section{MATERIALS AND METHODS}

This study employed both quantitative and qualitative research methods. Research methodology is concerned with the explanation of the essentials of the research process and these include data collection techniques, sampling frame, sampling size, questionnaire design as well as data analysis and presentation. There is need to use scientific method to impact of population growth on the socio-economic status of households in Somolu and critically looking at the impact of the existing situation on the people in the environment.

Research design: In the view by Andrew, research design is the set of methods and procedures used in collecting and analyzing measures of the variables specified in the research problem. It is a framework has

been created to find answers to research questions. This study deployed the survey research design. This study was designed to access the impact of population growth on the socio-economic status of households in Somolu local government area.

Sources of data: Data for this research work was collected from primary and secondary source.

Primary source: The primary source relates to fresh or raw data obtained directly from the field. For the resident's survey, householders will be the source of data. This was done by administering structured questionnaire to the respondents during the household survey. Photograph of object of interest was procured.

Secondary source: Secondary source of data collection refers to data already collected, processed, analyzed, sometimes interpreted and reconstructed by other researchers. Secondary data for this research was obtained from journals, online publications, conference and seminar papers, textbooks, dissertations, newspapers and other reputable online materials that have contents that covered the research work.

Research population: Research population is the audience which a research instrument is set to address (Okoko, 2000). A research population is generally a large collection of individuals or objects that is the main focus of a research. It is for the benefit of the population that researches are done. The population of Somolu based on the census carried out by National Population Commission (NPC, 2006) was put at 403,569 people. 
Sampling frame: Sampling frame is the source material or device from which a sample is drawn. The estimated 6790 households constitute the sample frame for this study.

Sample size: Sample is the part selected from the sample frame for a survey which gives appropriate representation of the composite population and allows generalization to be made on the aggregate population. 200 respondents were used as the sample size which were obtained using the following processes after paying several research visit to the Somolu local government area in order to gain the first hand information. It was gathered that the study area had over seven ward sections in the local government. The idea was to distribute at least 50 questionnaires in two streets within each ward, so, the figure of 200 households was arrived at due to time and available resources, the reason being to maintain a well distributed sampling in order to achieve a maximized opinion on socio economic activities from respondents within the study area for clarity of information.

Sampling technique: A simple random sampling technique was deployed for the survey. The survey was not limited to household heads only in cases where the household head is not around during the survey an adult household member that has insightful information about the focus of this research was selected.

Research instruments: Data collection is the process of gathering and measuring information on targeted variables in an established systematic fashion which then enables one to answer relevant questions and evaluate outcomes in the research survey conducted. The following instruments are were used to collect data for this research.

Questionnaire was administered for the household survey. The first section covers Demographic Characteristics (DC); second section is on Household Information (HI); third section is on general Perception on the Impact of Population (PIP). The demographic profile is of individual characteristics of each household head (sex, age, marital status, ethnicity, level of educational background and household income).

Camera-this was used to take pictures of existing conditions of the area. Observation technique: to capture scenes of interest that is paramount to the originality and success of this study.

Procedure for data collection: The objective of the data collection procedure is to ensure that an efficient and accurate data collection process is conducted. This section discusses the process of data collection for this study. The data collection method for this study used a written survey questionnaire. The survey questionnaires were validated following a pilot test and reliability test. Field trip was taken and used to distribute questionnaires within the Somolu local government area of different households from Bariga, Fadeyi, Bajulaiye, Ilaje/Chemist.
Methods of data analysis: Using descriptive statistics, the collected data was simplified and organized. Descriptive statistics provide background information for sample characteristics. Background information includes the profiles of the respondents (gender, role, educational level, sex, household size). Frequency distributions and percentages provided an overview of the collected data. These were displayed in the form of graphs and tables.

Discussion of findings: This chapter contained data, information and findings from the study area. Focus was on the analysis of the data collected based on the sample size taken from the population of the study areas. About 200 questionnaires were administered and retrieved from the respondents in Somolu local government. Descriptive illustration such as table, plates, diagrams and charts were used to present the findings from the survey.

Demographic configuration of household members and fertility trends: Table 1 shows the response of the respondents based on their demographic configuration of in terms of fertility trends for the study area. It was revealed from the table that majority of the respondents in Bariga and Bajulaiye that responded to the questions put forward to them are between the ages of 36-45 years of age while respondents between the ages of 25-35 years of age responded more in Fadeyi and Ilaje/Chemist. This implies that majority of the respondents are adults and are able to understand the questions put forward to them. The table also shows the gender of the respondents that majority of the respondents who attempted the questions were males in Bariga, Fadeyi and Ilaje/Chem ist while in Bajulaiye majority of the respondents were females.

Table 1 also reveals that majority of the respondents in Bariga, Fadeyi, Bajulaiye and Ilaje/Chemist were single. Table 1 also shows that majority of the respondent in Bariga, Fadeyi, Bajulaiye and Ilaje/Chemist had tertiary education which implies that they are well informed and are able to answer the questions put forward to them. The table also reveals that majority of the respondents monthly income is between N50,000-N99,000 in Bariga, Fadeyi, Bajulaiye and Ilaje/Chemist. The table also shows that majority of the respondents in Bariga and Ilaje/Chem ist works in the private sector while in Fadeyi and Bajulaiye are self-employed.

Table 1 also reveals that majority of respondents in Bariga, Fadeyi and Ilaje/Chemist currents family size are between 5-7 while the current family size in Bajulaiye is between 2-4. The table also shows that family size increase between 2008-2018 in Bariga, Bajulaiye and Ilaje/Chemist is 0 while in Fadeyi is between 1-2.

Field survey as depicted with Fig. 2 shows the age of respondents across the four districts in Somolu LGA. It is observed that the population of youths within the ages of 25-35 dom inates across the four zones. Bajulaiye also has the highest number of youths. There is very little number of aged people over 65 years compared to the rest of the participants. 


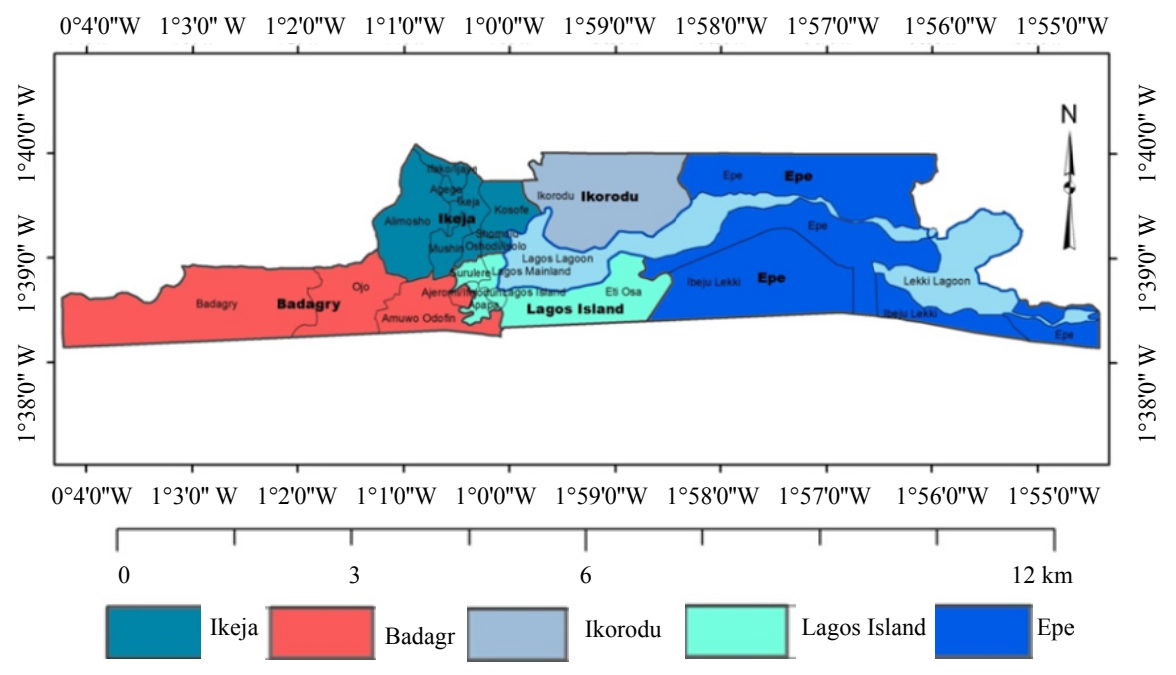

Fig. 2: Somolu local government area within the regional setting; Lagos state Ministry of Physical Planning and Urban Development in 2018

Respondents response on the relationship between population growth and social status: Table 2 shows the analysis of respondents response to the questions put forward to them on the relationship between population growth and social status. The tables reveals that majority of the respondents in all the study area that is Bariga, Fadeyi, Bajulaiye and Ilaje/Chemist stated that the effect of population size on livelihood is negative. It was also revealed that majority of the respondents agreed in all the study area that is Bariga, Fadeyi, Bajulaiye and Ilaje/Chemist that the effect of population size on health is negative. This implies that there is no significant relationship between population growth and social status (Health and education) of households in Somolu local government area.

Respondents response on the relationship between population growth and economic status: Table 3 shows the analysis of respondent's response to the questions put forward to them on the relationship between population growth and economic status. The tables reveals that majority of the respondents in all the study area that is Bariga, Fadeyi, Bajulaiye and Ilaje/Chemist stated that the effect of population size on schooling is negative. It was also revealed that majority of the respondents agreed in all the study area that is Bariga, Fadeyi, Bajulaiye and Ilaje/Chemist that the effect of population size on accommodation is negative. This implies that there is no significant relationship between population growth and economic status of households in Somolu local government area.

Household members perception on the impact of demographic changes: In other to evaluate the influence of household member's perception on demographic
Table 1: Demographic configuration of household members and fertility trends

\begin{tabular}{|c|c|c|c|c|}
\hline Variable & Bariga & Fadeyi & Bajulaiye & Ilaje/Chemist \\
\hline \multicolumn{5}{|c|}{ Age of the respondents (years) } \\
\hline \multirow[t]{2}{*}{$25-35$} & 16 & 20 & 25 & 15 \\
\hline & $32 \%$ & $64 \%$ & $50 \%$ & $30 \%$ \\
\hline \multirow[t]{2}{*}{$36-45$} & 18 & 16 & 22 & 19 \\
\hline & $36 \%$ & $32 \%$ & $44 \%$ & $38 \%$ \\
\hline \multirow[t]{2}{*}{$46-64$} & 10 & 9 & 3 & 11 \\
\hline & $20 \%$ & $18 \%$ & $6 \%$ & $22 \%$ \\
\hline \multirow[t]{2}{*}{$>65$} & 6 & 5 & 0 & 5 \\
\hline & $12 \%$ & $10 \%$ & $0 \%$ & $10 \%$ \\
\hline \multirow[t]{2}{*}{ Total } & 50 & 50 & 50 & 50 \\
\hline & $100 \%$ & $100 \%$ & $100 \%$ & $100 \%$ \\
\hline \multicolumn{5}{|c|}{ Gender of the respondents } \\
\hline \multirow{2}{*}{ Male } & 32 & 26 & 24 & 30 \\
\hline & $64 \%$ & $64 \%$ & $48 \%$ & $60 \%$ \\
\hline \multirow[t]{2}{*}{ Female } & 18 & 24 & 26 & 20 \\
\hline & $36 \%$ & $36 \%$ & $52 \%$ & $40 \%$ \\
\hline \multirow[t]{2}{*}{ Total } & 50 & 50 & 50 & 50 \\
\hline & $100 \%$ & $100 \%$ & $100 \%$ & $100 \%$ \\
\hline \multicolumn{5}{|c|}{ Marital status of the respondents } \\
\hline \multirow[t]{2}{*}{ Single } & 26 & 28 & 34 & 24 \\
\hline & $52 \%$ & $56 \%$ & $68 \%$ & $48 \%$ \\
\hline \multirow[t]{2}{*}{ Married } & 16 & 21 & 16 & 18 \\
\hline & $32 \%$ & $42 \%$ & $32 \%$ & $36 \%$ \\
\hline \multirow[t]{2}{*}{ Divorced } & 4 & 1 & 0 & 6 \\
\hline & $8 \%$ & $2 \%$ & $0 \%$ & $12 \%$ \\
\hline \multirow[t]{2}{*}{ Widowed } & 4 & 0 & 0 & 2 \\
\hline & $8 \%$ & $0 \%$ & $0 \%$ & $4 \%$ \\
\hline \multirow[t]{2}{*}{ Total } & 50 & 50 & 50 & 50 \\
\hline & $100 \%$ & $100 \%$ & $100 \%$ & $100 \%$ \\
\hline \multicolumn{5}{|c|}{ Educational level of respondents } \\
\hline \multirow[t]{2}{*}{ No formal education } & 6 & 13 & 7 & 4 \\
\hline & $12 \%$ & $26 \%$ & $14 \%$ & $8 \%$ \\
\hline \multirow[t]{2}{*}{ Primary Sch. } & 16 & 12 & 10 & 18 \\
\hline & $32 \%$ & $24 \%$ & $20 \%$ & $36 \%$ \\
\hline \multirow[t]{2}{*}{ Secondary Sch. } & 18 & 8 & 13 & 20 \\
\hline & $36 \%$ & $16 \%$ & $26 \%$ & $40 \%$ \\
\hline \multirow[t]{2}{*}{ Tertiary Sch. } & 12 & 17 & 20 & 10 \\
\hline & $24 \%$ & $34 \%$ & $40 \%$ & $20 \%$ \\
\hline \multirow[t]{2}{*}{ Total } & 50 & 50 & 50 & 50 \\
\hline & $100 \%$ & $100 \%$ & $100 \%$ & $100 \%$ \\
\hline
\end{tabular}


Environ. Res. J., 13 (1-4): 21-34, 2019

Table 1: Continue

\begin{tabular}{|c|c|c|c|c|}
\hline \multicolumn{5}{|c|}{ Monthly income (村) of the respondents } \\
\hline $50,000-99,000$ & $\begin{array}{l}27 \\
54 \%\end{array}$ & $\begin{array}{l}32 \\
64 \%\end{array}$ & $\begin{array}{l}32 \\
64 \%\end{array}$ & $\begin{array}{l}24 \\
48 \%\end{array}$ \\
\hline \multirow[t]{2}{*}{$100,000-199,000$} & 12 & 11 & 7 & 15 \\
\hline & $24 \%$ & $22 \%$ & $14 \%$ & $30 \%$ \\
\hline \multirow[t]{2}{*}{$200,000-299,000$} & 6 & 7 & 8 & 7 \\
\hline & $12 \%$ & $14 \%$ & $16 \%$ & $14 \%$ \\
\hline $300,00-399,000$ & 4 & 0 & 3 & $\begin{array}{l}3 \\
6 \%\end{array}$ \\
\hline$>400,000$ & 1 & 0 & 0 & 24 \\
\hline \multirow[t]{2}{*}{ Total } & $\begin{array}{l}2 \% \\
50\end{array}$ & $\begin{array}{l}0 \% \\
50\end{array}$ & $\begin{array}{l}0 \% \\
50\end{array}$ & $\begin{array}{l}48 \% \\
50\end{array}$ \\
\hline & $100 \%$ & $100 \%$ & $100 \%$ & $100 \%$ \\
\hline \multicolumn{5}{|l|}{ Type of occupation } \\
\hline Self-employed & $\begin{array}{l}13 \\
26 \%\end{array}$ & $\begin{array}{l}18 \\
36 \%\end{array}$ & $\begin{array}{l}14 \\
28 \%\end{array}$ & $\begin{array}{l}15 \\
30 \%\end{array}$ \\
\hline Public sector & $\begin{array}{l}12 \\
24 \%\end{array}$ & $\begin{array}{l}11 \\
22 \%\end{array}$ & $\begin{array}{l}12 \\
24 \%\end{array}$ & $\begin{array}{l}10 \\
20 \%\end{array}$ \\
\hline Private sector & $\begin{array}{l}17 \\
34 \%\end{array}$ & $\begin{array}{l}9 \\
18 \%\end{array}$ & $\begin{array}{l}13 \\
26 \%\end{array}$ & $\begin{array}{l}16 \\
32 \%\end{array}$ \\
\hline Unemployed & $\begin{array}{l}8 \\
16 \%\end{array}$ & $\begin{array}{l}12 \\
24 \%\end{array}$ & $\begin{array}{l}11 \\
22 \%\end{array}$ & $\begin{array}{l}9 \\
18 \%\end{array}$ \\
\hline Total & $\begin{array}{l}50 \\
100 \%\end{array}$ & $\begin{array}{l}50 \\
100 \%\end{array}$ & $\begin{array}{l}50 \\
100 \%\end{array}$ & $\begin{array}{l}50 \\
100 \%\end{array}$ \\
\hline \multicolumn{5}{|c|}{ Current family size } \\
\hline $2-4$ & $\begin{array}{l}16 \\
32 \%\end{array}$ & $\begin{array}{l}18 \\
36 \%\end{array}$ & $\begin{array}{l}24 \\
48 \%\end{array}$ & $\begin{array}{l}15 \\
30 \%\end{array}$ \\
\hline $5-7$ & $\begin{array}{l}26 \\
52 \%\end{array}$ & $\begin{array}{l}24 \\
48 \%\end{array}$ & $\begin{array}{l}12 \\
24 \%\end{array}$ & $\begin{array}{l}27 \\
54 \%\end{array}$ \\
\hline $8-10$ & $\begin{array}{l}6 \\
12 \%\end{array}$ & $\begin{array}{l}8 \\
16 \%\end{array}$ & $\begin{array}{l}8 \\
16 \%\end{array}$ & $\begin{array}{l}7 \\
14 \%\end{array}$ \\
\hline $11-13$ & $\begin{array}{l}2 \\
4 \%\end{array}$ & $\begin{array}{l}0 \\
0 \%\end{array}$ & $\begin{array}{l}6 \\
8 \%\end{array}$ & $\begin{array}{l}1 \\
2 \%\end{array}$ \\
\hline Total & $\begin{array}{l}50 \\
100 \%\end{array}$ & $\begin{array}{l}50 \\
100 \%\end{array}$ & $\begin{array}{l}50 \\
100 \%\end{array}$ & $\begin{array}{l}50 \\
100 \%\end{array}$ \\
\hline \multicolumn{5}{|c|}{ Family size increase between $2009-2019$} \\
\hline 0 & $\begin{array}{l}17 \\
34 \%\end{array}$ & $\begin{array}{l}14 \\
28 \%\end{array}$ & $\begin{array}{l}19 \\
38 \%\end{array}$ & $\begin{array}{l}16 \\
32 \%\end{array}$ \\
\hline $1-2$ & $\begin{array}{l}14 \\
28 \%\end{array}$ & $\begin{array}{l}16 \\
32 \%\end{array}$ & $\begin{array}{l}8 \\
16 \%\end{array}$ & $\begin{array}{l}15 \\
30 \%\end{array}$ \\
\hline 3-4 & $\begin{array}{l}11 \\
22 \%\end{array}$ & $\begin{array}{l}13 \\
26 \%\end{array}$ & $\begin{array}{l}12 \\
24 \%\end{array}$ & $\begin{array}{l}12 \\
24 \%\end{array}$ \\
\hline $5-6$ & $\begin{array}{l}8 \\
16 \%\end{array}$ & $\begin{array}{l}7 \\
14 \%\end{array}$ & $\begin{array}{l}11 \\
22 \%\end{array}$ & $\begin{array}{l}7 \\
14 \%\end{array}$ \\
\hline Total & $\begin{array}{l}16 \% \\
50 \\
100 \%\end{array}$ & $\begin{array}{l}14 \% \\
50 \\
100 \%\end{array}$ & $\begin{array}{l}22 \% \\
50 \\
100 \%\end{array}$ & $\begin{array}{l}50 \\
100 \%\end{array}$ \\
\hline
\end{tabular}

Table 2: Relationship between population growth and social status

\begin{tabular}{|c|c|c|c|c|}
\hline Variable & Bariga & Fadeyi & Bajulaiye & Ilaje/Chemist \\
\hline \multicolumn{5}{|c|}{ Effect of population size on schooling } \\
\hline \multirow[t]{2}{*}{ Positive } & 0 & 0 & 0 & 0 \\
\hline & $0 \%$ & $0 \%$ & $0 \%$ & $0 \%$ \\
\hline \multirow[t]{2}{*}{ Negative } & 42 & & 43 & 43 \\
\hline & $84 \%$ & 36 & $86 \%$ & $86 \%$ \\
\hline \multirow[t]{2}{*}{ Indifferent } & 8 & $72 \%$ & 7 & 7 \\
\hline & $16 \%$ & & $14 \%$ & $14 \%$ \\
\hline \multirow[t]{2}{*}{ Total } & 50 & 14 & 50 & 50 \\
\hline & $100 \%$ & $\begin{array}{l}28 \% \\
50 \\
100 \%\end{array}$ & $100 \%$ & $100 \%$ \\
\hline \multicolumn{5}{|c|}{ Effect of population size on health } \\
\hline Positive & $\begin{array}{l}0 \\
0 \%\end{array}$ & $\begin{array}{l}0 \\
0 \%\end{array}$ & $\begin{array}{l}0 \\
0 \%\end{array}$ & $\begin{array}{l}0 \\
0 \%\end{array}$ \\
\hline \multirow[t]{2}{*}{ Negative } & 38 & 39 & 41 & 39 \\
\hline & $76 \%$ & $78 \%$ & $82 \%$ & $78 \%$ \\
\hline \multirow[t]{2}{*}{ Indifferent } & 12 & 11 & 9 & 11 \\
\hline & $24 \%$ & $22 \%$ & $18 \%$ & $22 \%$ \\
\hline \multirow[t]{2}{*}{ Total } & 50 & 50 & 50 & 50 \\
\hline & $100 \%$ & $100 \%$ & $100 \%$ & $100 \%$ \\
\hline
\end{tabular}

Table 3: Relationship between population growth and economic status \begin{tabular}{lllll}
\hline Variable & Bariga & Fadeyi & Bajulaiye & Ilaje/Chemist
\end{tabular} Effect of population size on livelihood

\begin{tabular}{lllll} 
Positive & 0 & 0 & 0 & 0 \\
& $0 \%$ & $0 \%$ & $0 \%$ & $0 \%$ \\
Negative & 36 & 44 & 45 & 39 \\
& $72 \%$ & $88 \%$ & $90 \%$ & $78 \%$ \\
Indifferent & 14 & 6 & 5 & 12 \\
& $28 \%$ & $12 \%$ & $10 \%$ & $24 \%$ \\
Total & 50 & 50 & 50 & 50 \\
\multicolumn{5}{c}{ Effect of population size on accommodation } \\
Positive & 6 & 1 & 0 & $100 \%$ \\
& $12 \%$ & $2 \%$ & $0 \%$ & 0 \\
Negative & 42 & 45 & 47 & $0 \%$ \\
Indifferent & $84 \%$ & $90 \%$ & $94 \%$ & $80 \%$ \\
& 2 & 4 & 3 & $10 \%$ \\
Total & $4 \%$ & $8 \%$ & $6 \%$ & $20 \%$ \\
& 50 & 50 & 50 & 50 \\
& $100 \%$ & $100 \%$ & $100 \%$ & $100 \%$ \\
\hline
\end{tabular}

Field survey in 2019

Table 4: Model summary

\begin{tabular}{ccccc}
\hline Model & $\mathrm{R}$ & $\mathrm{R}^{2}$ & Adjusted $\mathrm{R}^{2}$ & Std. Error of the estimate \\
\hline
\end{tabular}
\begin{tabular}{llllr}
\hline 1 & $0.906 \mathrm{a}$ & 0.820 & 0.819 & 0.63647
\end{tabular}

a. Predictors: (Constant), household member's perception

Table 5: ANOVA $^{a}$

\begin{tabular}{lrlrcc}
\hline Model & $\begin{array}{r}\text { Sum of } \\
\text { squares }\end{array}$ & df & \multicolumn{1}{c}{$\begin{array}{l}\text { Mean } \\
\text { square }\end{array}$} & F-value & Sig. \\
\hline Regression & 426.106 & 1 & 426.106 & 1051.878 & $0.000 \mathrm{~b}$ \\
1 Residual & 93.576 & 231 & 0.405 & & \\
Total & 519.682 & 232 & & & \\
\hline
\end{tabular}

a. Dependent variable: demographic changes

b. Predictors: (Constant), household member's perception

Table 6: Coefficients ${ }^{\mathrm{a}}$

\begin{tabular}{|c|c|c|c|c|c|}
\hline \multirow[b]{2}{*}{ Model } & \multicolumn{2}{|c|}{$\begin{array}{l}\text { Unstandardized } \\
\text { coefficients }\end{array}$} & \multirow{2}{*}{$\begin{array}{l}\text { Standardized } \\
\text { coefficients } \\
---- \\
\text { Beta } \\
\end{array}$} & \multirow[b]{2}{*}{ t-value } & \multirow[b]{2}{*}{ Sig. } \\
\hline & B & $\mathrm{SE}$ & & & \\
\hline (Constant) & 11.038 & 0.116 & & 7.325 & 0.000 \\
\hline $\begin{array}{l}1 \text { household } \\
\text { member's perceptio }\end{array}$ & 15.063 & 0.033 & 0.906 & 32.433 & 0.000 \\
\hline
\end{tabular}

a. Dependent variable: demographic changes

changes on in Somolu Local Government Area (LGA) a simple linear regression analysis was done. The result of the result using the Statistical Package for Social Sciences (SPSS) was stated below (Table 4-6).

\section{RESULTS AND DISCUSSION}

The linear regression estimates the coefficient of the linear equation, involving one independent variable that best predict the value of the dependent variables. The dependent variables is demographic changes while the independent variable is household members perception. The table above shows that R2 is 0.820 with F-value of 1051.878 and a significance level of 0.000 which is considered to be $<0.05$. Hence, we therefore conclude that household member's perception influences the demographic changes in Somolu Local Government 
Area (LGA). The highest proportion of the population felt that the increase in population had a negative effect on their livelihood. They also felt that the increase in population had a negative effect on schooling at all levels of education. The increase in population also caused an increase in competition for admission into schools. Housing and accommodation services were also affected by the increase in population.

Summary of findings: It was observed that the population of youths within the ages of 25-35 dominates across the four zones. A high proportion of individuals were within the ages of 36-45. This characterizes a population of fertile, actively reproducing individuals. The male population seems to dominate in all the zones, compared to the females. There were a higher proportion of unmarried individuals among which might also be dating, in courtship or living with a significant other without a legal union. There are also a good number of married couples living together in the zones. A high number of participants from Ilaje/Chemist and Bajulaiye had no formal education. More individuals form Fadeyi were educated up to the tertiary level and the average were distribution was across the primary and secondary levels of education. The highest proportion of the population felt that the increase in population had a negative effect on their health including but not limited to, access to healthcare services access to a clean environment, access to childcare and maternity services.

Majority of the population were income earners within the range of $\$ 50,000-\mathrm{N} 99,000$. This reflects dominance of the lower class in this area. Higher income earners were present but few. The occupations of the participants in Somolu were evenly distributed. The highest proportions of participants in Fadeyi were unemployed. The highest proportion of participants in Bajulaiye and Ilaje/Chemist were working in the private sector. The size of most families in this area is within 2-7. This reflects newlywed couples without children and families with 2-5 children. Within the space of 10 years, most of these families experienced an increase in numbers by 1 and 2 additions. This could be either by increase in birth rate or marriages. Notable increase in family size by 3-7 additions was also observed. The trend of family size additions decreased progressively from 1 through 6 additions.

The highest proportion of the population felt that the increase in population had a negative effect on their livelihood. They also felt that the increase in population had a negative effect on schooling at all levels of education. The increase in population also caused an increase in competition for admission into schools. Housing and accommodation services were also affected by the increase in population. No notable increase in income was observed commensurate to the increase in population of their households.

\section{CONCLUSION}

This study attempted to examine the impact of population growth on the socio-economic status of households in Somolu local government area. Findings evidenced a trend of large families with sources of income that is insufficient or not sufficient enough to cater for its members. The households also felt that the effect of increase in population was negative with relation to the health, accommodation, income and livelihood.

\section{RECOMMENDATIONS}

- Nigeria, the most populous country in Africa reflects its large population chiefly in Lagos state

- Rapid population growth rate, coupled with wide spread poverty is characteristic of this population, due to high immigration patterns and fertility trends

- This research, so, far has revealed a trend of large families with sources of income that is insufficient or not sufficient to cater for its members

- Further studies should be conducted with a larger population size in order to better explain the relationships

\section{REFERENCES}

Agani, F.N., T. Wenzel, B. Maxhuni, F. Rushiti and I. Abdullah, 2006. Long-term sequelae of war: Social functioning in Kosovo six years after the war. Danish Refugee Council, Pristina, Kosovo.

Amaza, P.S., J.C. Umeh, J. Helsen and A.O. Adejobi, 2006. Determinants and measurements of food insecurity in Nigeria: Some empirical policy guide. Proceedings of the International 2006 Annual Meeting on Association of Agricultural Economists (IAAE'06), August 12-18, 2006, Queensland, Australia, pp: 1-15.

Babatunde, R.O., O.A. Omotesho and O.S. Sholotan, 2007. Factors influencing food security status of rural farming households in north central Nigeria. Agric. J., 2: 351-357.

Bane, M.J. and D.T. Ellwood, 1986. Slipping into and out of poverty: The dynamics of spells. J. Hum. Resour., 21: 1-23.

Banerjee, A.V. and A.F. Newman, 1991. Risk-bearing and the theory of income distribution. Rev. Econ. Stud., 58: 211-235.

Baulch, B., 1996. Neglected trade offs in poverty measurement. IDS. Bull., 27: 36-42. 
Bollen, K.A., J.L. Glanville and G. Stecklov, 2002. Economic status proxies in studies of fertility in developing countries: Does the measure matter? Popul. Stud., 56: 81-96.

Bongaarts, J., 1978. A framework for analyzing the proximate determinants of fertility. Popul. Dev. Rev., 4: $105-132$.

Brooks-Gunn, J., G.J. Duncan, P.K. Klebanov and N. Sealand, 1993. Do neighborhoods influence child and adolescent development?. Am. J. Sociology, 99: 353-395.

Caroline, O. Albert and I.I. Benjamin, 2009. Issues in developing a national policy on agricultural extension service in Nigeria: The perception of extension professionals. Agric. J., 4: 22-26.

Carter, M. and J. May, 1999. Poverty, livelihood and class in rural South Africa. World Develop., 27: 1-20.

Dao, M.Q., 2012. Population and economic growth in developing countries. Int. J. Acad. Res. Bus. Soc. Sci., 2: 6-17.

Demeny, P. and G. McNicoll, 2003. Encyclopedia of Population. Macmilian Reference, New York, USA., ISBN-13: 978-0028656779, Pages: 1000.

FMH., 1988. National policy on population for development, unity, progress and self-reliance. Federal Republic of Nigeria, Federal Ministry of Health, Lagos, Nigeria. https://searchworks. stanford.edu/view/2204640

Falkingham, J. and E. Namazie, 2002. A profile of poverty in Tajikistan. Discussion Paper, No. 39, ESRC Centre for the Analysis of Social Exclusion, London School of Economics, London, UK.

Filmer, D. and L.H. Pritchett, 2001. Estimating wealth effects without expenditure data-or tears: An application to educational enrollments in states of India. Demography, 38: 115-132.

Filmer, D., J.S. Hammer and L.H. Pritchett, 2000. Weak links in the chain: A diagnosis of health policy in poor countries. World Bank Res. Obse., 15: 199-224.
Grootaert, C. and R. Kanbur, 1995. The lucky few amidst economic decline: Distributional change in Coted. Ivoire as seen through panel data sets, 1985-1988. J. Develop. Studies, 31: 603-619.

Kothare, G.A., 2006. Determinants of food security among the rural farming households in Kwara State, Nigeria. Afr. J. Gen. Agric., 2: 234-272.

Kwaghe, P.V., 2006. Poverty profile and its determinants among farming households in Borno State, Nigeria. Ph.D. Thesis, Department of Agricultural Economics and Extension, University of Maiduguri, Nigeria, Maiduguri, Nigeria.

Maxwell, D., R. Caldwell and M. Langworthy, 2008. Measuring food insecurity: Can an indicator based on localized coping behaviors be used to compare across contexts? Food Policy, 33: 533-540.

Mckenzie, D.G., 2005. Food securityassessment, regional overview information bulletin. Economic Research Servic, Washington, DC., USA.

Montgomery, A., D. Axel and R. Smith, 2000. A special report on feeding the world: The 9 billion-people question. The Econom ist, Westminster, London, UK.

Naxwell, K.O., 1999. Determinant of food security in Bauchiarea of Northern Guinea Savanna of Nigeria. Ph.D. Thesis, Department of Agricultural Economics, University of Ibadan, Ibadan, Nigeria.

Oluyole, K.A., O.A. Oni, B.T. Omonona and K.O. Adenegan, 2009. Food security among cocoa farming households of Ondo State, Nigeria. J. Agric. Biol. Sci., 4: 7-13.

Ravallion, M. and S. Chen, 1997. What can new survey data tell us about recent changes in income distribution and poverty? World Bank Econ. Rev., 11: 357-382.

Ruel, M.T., 2003. Operationalizing dietary diversity: A review of measurement issues and research priorities. J. Nutr., 133: 3911S-3926S.

Sahn, D.E. and D. Stifel, 2003. Exploring alternative measures of welfare in the absence of expenditure data. Rev. Income Wealth, 49: 463-489.

Zimmerman, F.J. and M.R. Carter, 2003. Asset smoothing, consumption smoothing and the reproduction of inequality under risk and subsistence constraints. J. Dev. Econ., 71: 233-260. 